\title{
Long-term results after left ventricular aneurysmectomy
}

\author{
JAN ERIK OTTERSTAD, ODDBJØRN CHRISTENSEN, \\ KJELL LEVORSTAD, SIGURD NITTER-HAUGE \\ From the Medical Department B, Surgical Department A, and Radiological Department, University \\ Hospital, Rikshospitalet, Oslo, Norway
}

SUMMARY Twenty-six patients ( 21 men and five women) with a mean age of 54.8 years have been reinvestigated nine to 62 months (mean 29.7) after left ventricular aneurysmectomy. Preoperatively left ventricular angiography disclosed an anterior aneurysm in all cases, which was large in $15(58 \%)$ and small to medium in $11(42 \%)$. At follow-up a large residual aneurysm was found in five $(19 \%)$, a small to medium one in $13(50 \%)$, and akinesia without aneurysm in eight $(31 \%)$. The sum of ST elevation $(\Sigma S T)$ in praecordial leads in the electrocardiogram was reduced from a mean value of $11.2 \mathrm{~mm}$ to $7.7 \mathrm{~mm}$. In no patient did ST segments return to normal after operation. Preoperatively, mean $\Sigma S T$ was identical in patients with large and with small to medium aneurysms. At reinvestigation mean $\Sigma S T$ was identical in patients with large and with small to medium residual aneurysms as well as in patients with akinesia. Left ventricular end-diastolic pressure before angiography was reduced from a mean value of $21.5 \mathrm{~mm}$ to $15.1 \mathrm{mmHg}$ and after angiography from $26.7 \mathrm{~mm}$ to $21.1 \mathrm{mmHg}$. Progression of coronary artery stenoses was a characteristic finding in patients whose left ventricular end-diastolic pressures did not return to normal. These patients had a longer follow-up time than those with no progression of coronary disease, who all showed an improvement in left ventricular end-diastolic pressure. Six patients who had coronary bypass grafting performed had unchanged left ventricular end-diastolic pressures at follow-up. The results indicate that progression of coronary artery disease may be responsible for an eventual further deterioration in left ventricular function after aneurysmectomy. Additional bypass grafting did not result in improved left ventricular function.

Since Cooley et al. ${ }^{1}$ first described the successful excision of left ventricular aneurysm using cardiopulmonary bypass, this operation has been widely performed with several reports of long-term symptomatic improvement. ${ }^{2-4}$ The objective effect on left ventricular function as shown by postoperative left heart catheterisation data, however, has been conflicting. Some authors have found improvement, ${ }^{356}$ but the findings of others have been inconclusive. ${ }^{4}{ }^{7-11}$ Brawley et al. ${ }^{12}$ found a correlation between prognosis and the preoperative status of the coronary arteries supplying the remaining part of the left ventricle. The functional outcome related to the status of the coronary arteries at long-term follow-up, however, has not been established. In addition, little is known about the electrocardiographic abnormalities after aneurysmectomy in relation to postoperative ventriculographic changes. ${ }^{13} 14$

Received for publication 13 August 1980
In the present study we have reinvestigated a total of 26 patients who survived left ventricular aneurysmectomy by at least nine months. In order to extend our knowledge about the relation between postoperative left ventricular function and the underlying coronary artery disease, the restudy also included selective coronary angiography. Finally, ST elevation in the pre- and postoperative electrocardiograms was studied and related to the findings of left ventriculography before and after operation.

\section{Subjects and methods}

A total of 26 patients, 21 men and five women, were reinvestigated nine to 62 months (mean 29.7) after left ventricular aneurysmectomy. All had had extensive anterior wall infarction. The time from the acute infarction to the operation averaged 21.9 months (range two to 72). The clinical indication for aneurysmectomy was cardiac failure in 13, angina 
pectoris in 10, and recurrent ventricular arrhythmias in three patients. Preoperatively, seven patients were in New York Heart Association (NYHA) grade IV, 15 were in grade III, and four were in grade II. The mean age of the patients at the time of operation was 54.8 years (range 32 to 69).

All patients were operated on using cardiopulmonary bypass, moderate hypothermia, and electrically-induced ventricular fibrillation. The left ventricle was vented via a cannula placed in the ascending aorta and aortic cross-clamping not exceeding 20 minutes was employed. The left ventricle was then explored, and mural thrombi removed. The aneurysm was excised leaving a small rim of scar tissue through which sutures over two Teflon pledgets were used to close the ventriculotomy. Additional aortocoronary bypass surgery using saphenous vein grafts was carried out in six patients.

Heart volume was radiologically estimated according to Lusted and Keats ${ }^{15}$ and expressed in $\mathrm{ml} / \mathrm{m}^{2}$ body surface area (upper normal limit $500 \mathrm{ml} / \mathrm{m}^{2}$ in men and $450 \mathrm{ml} / \mathrm{m}^{2}$ in women). Pre- and postoperative haemodynamic investigation included left heart catheterisation with measurements of left ventricular end-diastolic pressure before and two minutes after left ventriculography. Pressures were recorded with Elema Schoenander equipment (Transducer EMT 35 and Mingograph 81 ). The baseline was at the fourth intercostal space on the anterior axillary line. The left ventricular end-diastolic pressure was measured at the intercept between the "a" wave and the rapid ventricular upstroke. Left ventriculography was performed in the right anterior oblique position. The contrast material used was Isopaque coronar (metrizoate meglumine sodium calcium (58/g per l) $370 \mathrm{mg}$ $\mathrm{J}$ per $\mathrm{ml}$ ). Preoperatively, all patients had an aneurysm of the anterior wall, that is, a clear-cut saccular protrusion, in many cases including the apical region. Histological examination of the resected material disclosed severe fibrosis. The postoperative angiograms showed either a typical aneurysm or an akinetic area, that is absent or impaired contractions of the anterior wall usually also involving the apical region. The size of the aneurysm was evaluated by visual assessment. If it affected less than one-quarter of the anterior wall, it was graded as small, between one-quarter and onehalf as medium, and more than one-half as large.

Coronary angiography was performed in all patients before surgery (Judkins technique ${ }^{16}$ ). At reinvestigation this was omitted in two patients as clinically inadvisable. The angiograms were studied carefully to determine the progression of disease, that is the number of arteries progressing to total occlusion or showing a clear increase in percentage stenosis (increase in more than $25 \%$ of crosssectional area). In one of the two patients where coronary angiography was not repeated, the occurrence of a myocardial infarction according to WHO criteria was accepted as compatible with progression of disease.

Before and after operation a standard 12 lead electrocardiogram was recorded with the patients supine at rest (paper speed $50 \mathrm{~mm} / \mathrm{s}$ ). Care was taken to ensure that the position of praecordial electrodes was identical by using specially trained personnel. The voltage was adjusted so that $1 \mathrm{mV}$ was equal to $10 \mathrm{~mm}$. The heart rate was recorded directly from the electrocardiogram. Two patients with left bundle-branch block and two patients with a documented myocardial infarction at the follow-up study were excluded from the electrocardiographic study. None of the remaining 22 patients had left ventricular hypertrophy or the WPW syndrome on the electrocardiogram. ST elevation was measured exclusively in leads V1-6 with the aid of a hand lens to the nearest $0.5 \mathrm{~mm}$ at $80 \mathrm{~ms}$ from the J point according to the technique described by Gooch et al. ${ }^{14}$ The sum of ST elevations ( $\Sigma S T)$ in each electrocardiogram was expressed in mm. Additionally the largest ST elevation found in any single lead of each electrocardiogram was recorded and also expressed in $\mathrm{mm}$.

\section{STATISTICS}

All data are presented as arithmetic means \pm 1 standard deviation. The differences between preand postoperative measurements were tested by means of the $t$ test for paired data. $P$ values higher that 0.05 were not regarded as significant.

\section{Results}

\section{CLINICAL STATUS}

Before operation seven patients were in NYHA grade IV, 15 were in grade III, and four were in grade II. At reinvestigation, 21 patients $(81 \%)$ had improved their rating by one to two grades, four were unchanged, and one patient with a proven myocardial infarction in the observation period had deteriorated and was in grade III. The mean grade fell from $3 \cdot 1$ to $2 \cdot 0$.

\section{HEART SIZE}

Pre- and postoperative heart size determined radiologically was available in 23 patients. The mean heart volume was reduced from $637 \mathrm{ml} / \mathrm{m}^{2}$ (350 to 1090) to $519 \mathrm{ml} / \mathrm{m}^{2}(275$ to 880$)(\mathrm{p}<0.01)$. In 12 patients a reduction of $100 \mathrm{ml} / \mathrm{m}^{2}$ or more was 
found, in nine the heart volume was essentially unchanged, and in two an increase in heart volume of more than $100 \mathrm{ml} / \mathrm{m}^{2}$ had taken place.

\section{ANGIOGRAPHY}

(1) Left ventricular angiography before operation disclosed large aneurysms in 15 patients $(58 \%)$ and small to medium aneurysms in the remaining 11 patients $(42 \%)$. At reinvestigation 18 patients $(69 \%)$ had residual aneurysms, large in five and small to medium in 13, while seven patients had dyskinesia not fulfilling the criteria for a localised aneurysm. Repeat angiography was omitted in one patient as it was not considered safe.

(2) Selective coronary angiography showed that before operation all patients had a greater than 90 per cent obstruction or complete occlusion of the left anterior descending artery. Eleven patients had no further stenoses of the major coronary arteries, 11 had an additional significant stenosis exceeding 50 per cent of the luminal cross-sectional area in either the circumflex or the right coronary artery, that is double vessel disease, while the remaining four patients had significant stenoses of all three major vessels, that is triple vessel disease. At restudy 14 patients, seven with single and seven with double vessel disease, showed no progression of their coronary stenoses. In four patients, two with single and two with double vessel disease, an angiographically proven progression of coronary stenosis was demonstrable. Of the two patients in whom coronary angiography was not repeated, one had suffered from a cardiac infarction after surgery. In six patients a total of seven saphenous vein bypass grafts had been implanted. At reinvestigation all of these were patent and free from stenoses and the native coronary arteries were unchanged as well. Thus, in a total of five patients progression of coronary heart disease was found.

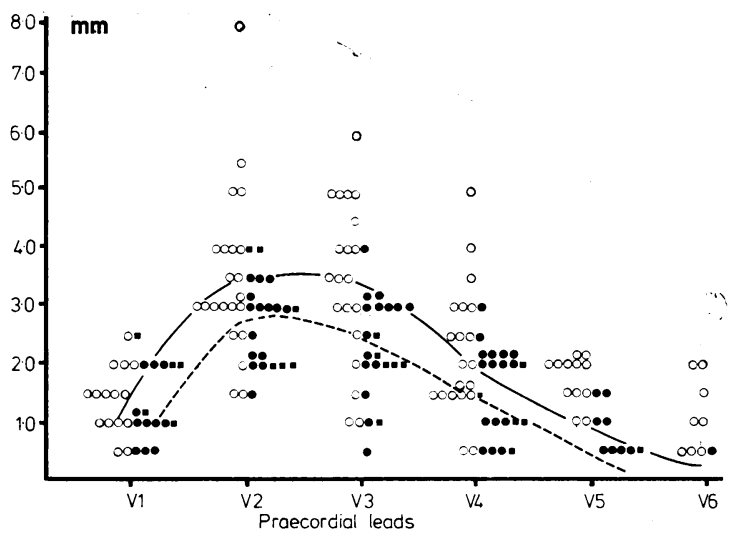

Fig. 1 ST elevation in praecordial leads (V1 to V6) before and after left ventricular aneurysmectomy. Circles denote values before operation, and squares after operation. Solid circles denote patients with persistent aneurysm at follow-up.

\section{ELECTROCARDIOGRAPHIC FINDINGS}

The mean heart rate before operation was 75.5 beats/min (range 45 to 106) and at reinvestigation 67.9 beats/min (range 45 to 102 ) (p $<0.05, p>0.01$ ) in the 22 patients studied for ST elevation. In all patients the ST segments in the praecordial leads were raised before operation. In none did the ST segments return to the baseline in all the leads after aneurysmectomy. The mean $\Sigma S T$ was significantly reduced from $11.2 \mathrm{~mm}(4.5$ to 23.5$)$ before to 7.7 $\mathrm{mm}(4.5$ to 10.5$)$ after operation $(\mathrm{p}<0.01)$. Fig. 1 shows the magnitude of ST elevations in leads V1-6 before and after operation. Only leads with elevation of at least $0.5 \mathrm{~mm}$ are included. The highest ST elevation was found in leads V1 and V3 with a mean value of $3.5 \mathrm{~mm}$ preoperatively. In these two leads mean ST elevation was reduced, by $0.7 \mathrm{~mm}$

Table 1 Relation between assessment of size of aneurysm on left ventricular angiography and sum of ST elevation $(\Sigma S T)$ in the praecordial leads before and after aneurysmectomy

\begin{tabular}{|c|c|c|c|c|c|c|c|c|c|}
\hline \multirow[b]{2}{*}{$\begin{array}{l}\text { Assessment of } \\
\text { of aneurysm }\end{array}$} & \multirow[b]{2}{*}{ No. } & \multicolumn{3}{|c|}{ Before operation } & \multirow[b]{2}{*}{ No. } & \multicolumn{4}{|c|}{ After operation } \\
\hline & & $\underset{\text { Mean }}{\boldsymbol{\Sigma} S T}(\mathrm{~mm})$ & (Range) & $\begin{array}{l}\text { Highest magnitude } \\
\text { in one lead (mm) } \\
\text { Mean (Range) }\end{array}$ & & $\underset{\text { Mean }}{\Sigma S T}(\mathrm{~mm})$ & (Range) & $\begin{array}{l}\text { Highest magt } \\
\text { in one lead } \\
\text { Mean }\end{array}$ & $\begin{array}{l}\text { zmitude } \\
\text { (mim) } \\
\text { (Range) }\end{array}$ \\
\hline $\begin{array}{l}\text { Large } \\
\text { Medium/small } \\
\text { Akinesia }\end{array}$ & $\begin{array}{r}13 \\
9 \\
0\end{array}$ & $\begin{array}{l}10 \cdot 7 \\
11.6\end{array}$ & $\begin{array}{l}(4 \cdot 0-16 \cdot 0) \\
(4 \cdot 5-23 \cdot 5)\end{array}$ & $\begin{array}{l}(2 \cdot 0-5 \cdot 5) \\
(1 \cdot 5-8 \cdot 0)\end{array}$ & $\begin{array}{r}3 \\
13 \\
6\end{array}$ & $\begin{array}{l}8 \cdot 3 \\
7 \cdot 8 \\
7 \cdot 3\end{array}$ & $\begin{array}{l}(4 \cdot 5-11 \cdot 5) \\
(5 \cdot 0-10 \cdot 5) \\
(4 \cdot 5-10 \cdot 5)\end{array}$ & $\begin{array}{l}2 \cdot 7 \\
2 \cdot 7 \\
2 \cdot 7\end{array}$ & $\begin{array}{l}(2 \cdot 5-3 \cdot 0) \\
(1 \cdot 5-4 \cdot 0) \\
(1 \cdot 5-4 \cdot 0)\end{array}$ \\
\hline
\end{tabular}


and $1.2 \mathrm{~mm}$, respectively, at reinvestigation. The reduction in the rest of the leads was less pronounced. In leads V2-4 practically all patients had ST elevation after operation while in lead V6 this was found in only one patient.

ST elevation before operation was indentical in 13 patients with large aneurysms compared with nine patients with small to medium aneurysms (Table 1). At reinvestigation three patients were considered to have large residual aneurysms, 13 small to medium aneurysms, and six akinesia. There were no differences in mean $\Sigma S T$ in these patient groups. Patients with akinesia were not distinguishable from those with residual aneurysms in respect of ST elevation in the praecordial leads (Fig. 1).

\section{LEFT VENTRICULAR END-DIASTOLIC} PRESSURE

Left ventricular end-diastolic pressure before angiography varied between 7 and $38 \mathrm{mmHg}$, with a mean of $21.5 \mathrm{mmHg}$, and 21 out of 26 patients $(81 \%)$ had values higher than the upper normal limit $(12 \mathrm{mmHg})$. After operation, left ventricular end-diastolic pressure varied between 5 and 36 $\mathrm{mmHg}$, with a mean value of $15.1 \mathrm{mmHg}$. Thirteen out of 26 patients $(50 \%)$ had values exceeding the

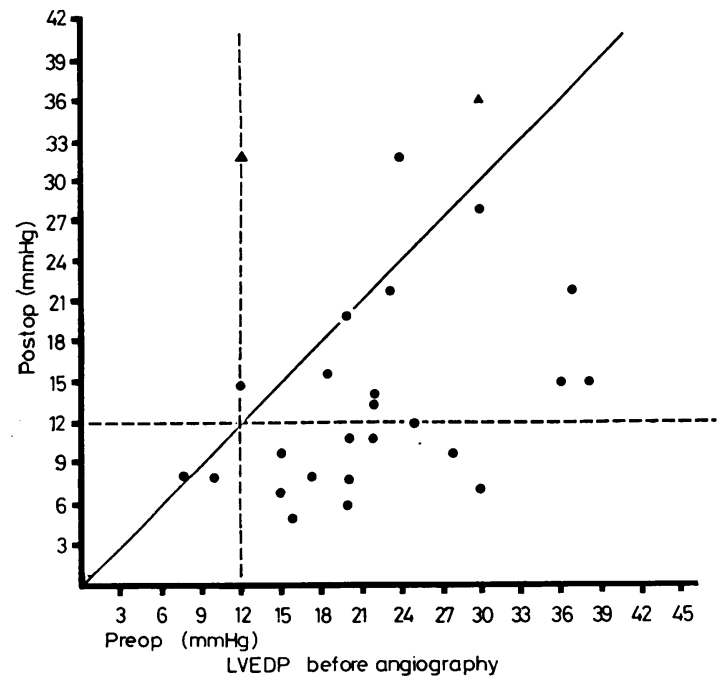

Fig. 2 Left ventricular end-diastolic pressure (LVEDP) before left ventricular angiography measured in patients before and after left ventricular aneurysmectomy. Interrupted lines indicate upper normal range. The solid line is the line of identity. Triangles indicate two patients with postoperative myocardial infarction.

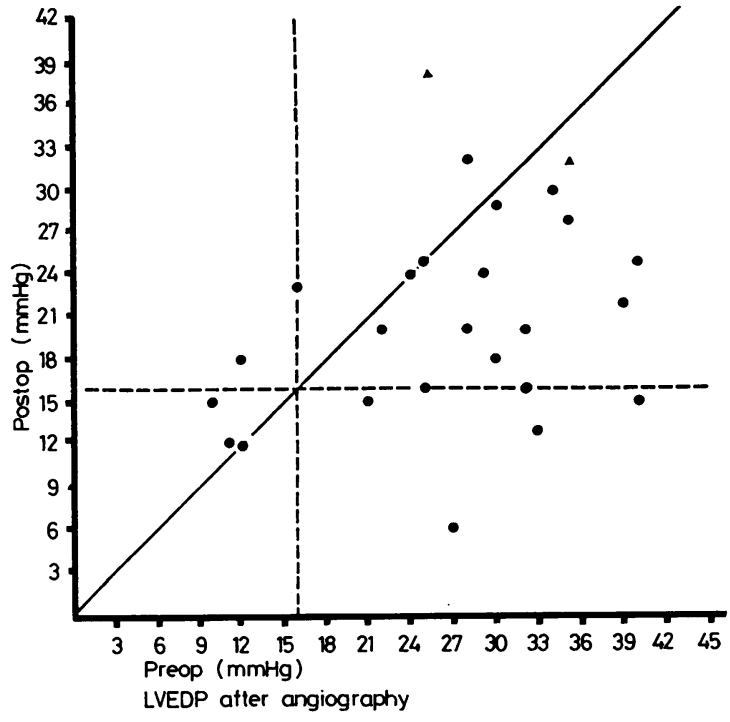

Fig. 3 Left ventricular end-diastolic pressure (LVEDP) measured after left ventricular angiography in patients before and after left venticular aneurysmectomy. Symbols as in Fig. 2.

upper normal limit (Fig. 2). The two patients with a myocardial infarction had high values at reinvestigation. The reduction in left ventricular end-diastolic pressure was significant $(\mathrm{p}<0.01)$.

Left ventricular end-diastolic pressure after angiography before operation varied between 10 and $40 \mathrm{mmHg}$, with a mean of $26.7 \mathrm{mmHg}$, and 21 out of $26(81 \%)$ had values above the upper normal limit (16 mmHg) (Fig. 3). After operation, left ventricular end-diastolic pressure varied between 6 and $38 \mathrm{mmHg}$, with a mean value of 21.1 $\mathrm{mmHg}(\mathrm{p}<0.01)$. Fig. 3 shows a postoperative return to normal of left ventricular end-diastolic pressure after angiography in $6 / 26$ patients $(23 \%)$, three having normal pressures before and afterwards.

Fig. 4 shows the pre- and postoperative values for left ventricular end-diastolic pressure before angiography when the patients are grouped according to the results of the coronary angiographic restudy. In group a, those with no progression of underlying coronary artery disease, abnormally raised left ventricular end-diastolic pressure values were reduced in all patients after operation, with one exception, and in about two-thirds of them became normal. In patients in group $b$, the five with progression of disease, as well as in those in group c, the six patients with additional bypass surgery, the left ventricular end-diastolic pressure was 

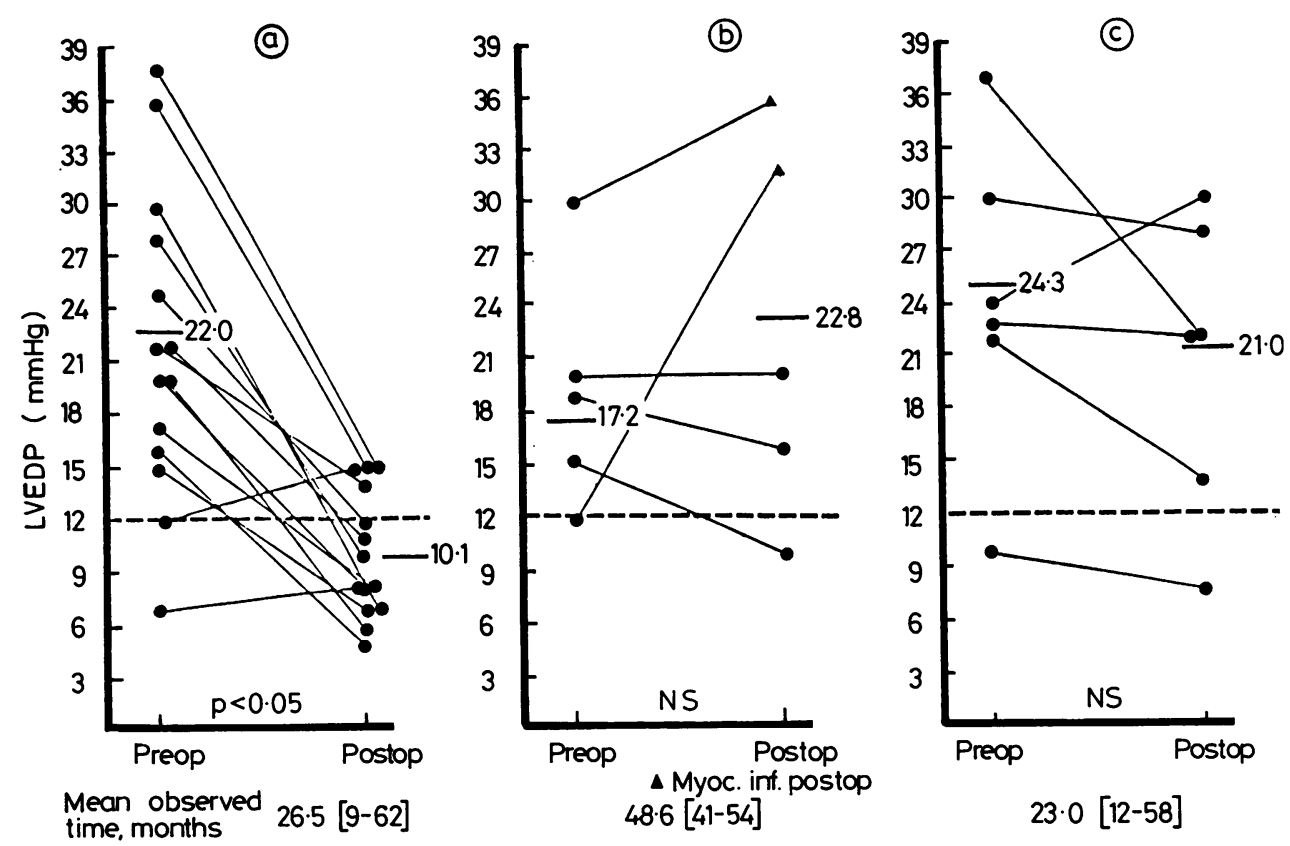

Fig. 4 Left ventricular end-diastolic pressure (LVEDP) measured before left ventricular angiography in patients studied before and after left ventricular aneurysmectomy. (a) Patients without angiographically demonstrable progression of underlying coronary artery disease. (b) Patients with progression of underlying coronary artery disease. Triangles indicate patients with postoperative myocardial infarction. (c) Patients with additional bypass surgery.

abnormally high both before and after aneurysmectomy, with two exceptions. Exceptionally high values were found in the two patients who had a myocardial infarction. It is noteworthy that the mean interval between operation and follow-up varied in the three subgroups, being definitely longer in group b than in the two other groups.

\section{CORRELATION BETWEEN CLINICAL}

IMPROVEMENT AND OBJECTIVE FINDINGS

Symptomatic improvement seemed to parallel the reduction in left ventricular end-diastolic pressure, while the size of the aneurysm, if present at recatheterisation, showed no clear correlation with clinical improvement (Table 2). Additionally, the clinical status of the patients with dyskinesia was identical to that of those with residual aneurysms. The reduction in left ventricular end-diastolic pressure was the same in patients with angina pectoris as in those who had heart failure as the presenting symptom before operation. The three patients with recurrent ventricular tachyarryth-

Table 2 Relation between clinical classification, left ventricular end-diastolic pressure before angiography, and size of aneurysm before and after left ventricular aneurysmectomy

\begin{tabular}{|c|c|c|c|c|c|c|c|c|c|c|c|c|c|c|c|}
\hline & \multicolumn{5}{|c|}{ Large aneurysm } & \multicolumn{5}{|c|}{ Small to medium aneurysm } & \multicolumn{5}{|c|}{ Dyskinesia } \\
\hline & No. & $\begin{array}{l}\text { NYHA } \\
\text { Mean }\end{array}$ & (Range) & $\begin{array}{l}\text { LVEDP } \\
\text { Mean }\end{array}$ & $\begin{array}{c}\text { (mmHg) } \\
(\text { Range) }\end{array}$ & No. & $\begin{array}{l}\text { NYHA } \\
\text { Mean }\end{array}$ & (Range) & $\begin{array}{l}\text { LVEDP } \\
\text { Mean }\end{array}$ & $\begin{array}{l}\text { (mmHg) } \\
\text { (Range) }\end{array}$ & No. & $\begin{array}{l}\text { NYHA } \\
\text { Mean }\end{array}$ & (Range) & $\begin{array}{l}\text { LVEDP } \\
\text { Mean }\end{array}$ & $\begin{array}{l}\text { (mmHg) } \\
\text { (Range) }\end{array}$ \\
\hline $\begin{array}{l}\text { Before } \\
\text { operation } \\
\text { After } \\
\text { operation }\end{array}$ & $\begin{array}{r}15 \\
5\end{array}$ & $\begin{array}{l}3 \cdot 3 \\
2 \cdot 2\end{array}$ & $\begin{array}{l}(2-4) \\
(1-4)\end{array}$ & $\begin{array}{l}20 \cdot 5 \\
15 \cdot 0\end{array}$ & $\begin{array}{l}(7-36) \\
(7-36)\end{array}$ & $\begin{array}{l}11 \\
13\end{array}$ & $\begin{array}{l}2.9 \\
1.8\end{array}$ & $\begin{array}{l}(2-4) \\
(1-3)\end{array}$ & $\begin{array}{l}23.9 \\
14 \cdot 4\end{array}$ & $\begin{array}{l}(12-38) \\
(6-28)\end{array}$ & $\begin{array}{l}0 \\
7\end{array}$ & $1 \cdot 7$ & $(1-2)$ & $14 \cdot 0$ & $(8-32)$ \\
\hline
\end{tabular}

LVEDP, left ventricular end-diastolic pressure; NYHA, New York Heart Association; one patient did not have repeat angiography performed because of high pressures at recatheterisation. 
mias, however, showed no significant improvement of left ventricular end-diastolic pressure.

\section{Discussion}

The results of aneurysmectomy in our patients are in accord with other studies, namely striking clinical improvement ${ }^{2-5} 7817$ and reduction of the radiologically estimated heart volume. ${ }^{14}$ The angiographic finding of a residual aneurysm in 70 per cent of our patients and akinesia in the remainder is also in keeping with the observations of others. ${ }^{45}$ It seems obvious that the area of the suture line with Teflon pledgets will be akinetic, and the presence of a residual aneurysm probably reflects non-excised, more or less fibrotic tissue which is left deliberately as support for sutures. Kitamura et al..$^{5}$ found the excised non-contractile area to be smaller than that estimated in the preoperative angiograms. From preoperative ventriculograms, Sesto et al. ${ }^{10}$ constructed a non-contractile and a transitional zone, that is a hypokinetic zone located between non-contractile and normally contracting parts of the left ventricle. The volume of aneurysm resected exceeded the volume of the non-contractile section, but was smaller than the sum of transitional and non-contractile volumes. They also reported a large akinetic area of the left ventricular wall after aneurysmectomy in one patient.

An interesting finding was that ST segment elevation persisted after aneurysmectomy and was not related to the size of the aneurysm either before or after operation. The exact mechanisms of the persistent ST elevation associated with left ventricular aneurysm after myocardial infarction remain unclear. ${ }^{18}$ To our knowledge no previous study has been performed comparing ST elevation in the electrocardiogram before and after aneurysmectomy with the findings at left ventriculography. Our results imply that it is the presence of a thinned, akinetic fibrotic portion of left ventricle that is responsible for the presence of ST elevation irrespective of the presence of a saccular protrusion at recatheterisation. Postoperatively, a rim of fibrotic tissue is always left behind representing "a window" reflecting unopposed repolarisation of the myocardial wall. The size of this "window" is obviously smaller than before operation, which is probably reflected in the significant reduction of ST elevation noted in our study. Gooch et al. ${ }^{14}$ also found a signficant reduction in ST elevation in 74 patients after left ventricular aneurysmectomy, but, like us, did not find that these returned to normal. Their patients were not recatheterised, but there was no relation between reduction in heart size, clinical improvement, and the persistence of ST elevation.
In order to study the mechanism of ST elevation in left ventricular aneurysm, Gerwitz et al. ${ }^{18}$ used a system of body-surface mapping. They suggest that the affected area itself is not the sole responsible factor but that pathological myocardium remote from the infarcted, fibrotic area may be the source. In our patients preoperatively ST elevation in those with single vessel disease and normal coronary arteries supplying the remaining myocardium did not differ from those with double or triple vessel disease.

Several previously published recatheterisation studies have been unable to show a significant reduction in left ventricular end-diastolic pressure after aneurysmectomy. ${ }^{6-11}$ Most of these reports have been based on relatively small groups of patients with a short follow-up period. In a larger study of 103 patients, Loop et al. ${ }^{3}$ found improved left ventricular performance in 69 per cent of the patients 18 months after aneurysmectomy as judged by the left ventriculogram, by left ventricular end-diastolic pressures, and by size of the residual scar. Kitamura et al. ${ }^{5}$ noted significantly reduced left ventricular end-diastolic pressures in nine patients examined three weeks to seven months after operation. In all these studies, however, except one, details about the progression of underlying coronary artery disease have usually not been given. There are difficulties in the selection of patients with respect to severity of coronary artery disease, in whether or not additional bypass surgery was performed, and finally in the criteria for the diagnosis of left ventricular aneurysm, and these factors may have influenced the results and may be partly responsible for the differences between the various investigators.

In the present study the improvement in left ventricular function was limited to patients who showed no progression of coronary artery disease. In this subgroup the reduction in left ventricular end-diastolic pressure was impressive, with a return to normal in most cases. The mean follow-up for these patients was approximately two years compared with four years in the patients with documented progression of coronary artery disease. In the latter left ventricular end-diastolic pressure was abnormally high before operation and at follow-up and did not change, implying that persistently poor left ventricular function after aneurysmectomy in this group may result from further impairment of blood supply to the contractile portion of the left ventricle. The progression of coronary artery disease takes time and this may explain the differences in the length of follow-up between the two subgroups, but further implies that, though in the short term left ventricular 
function appears to improve, eventually it is likely to deteriorate again.

In the six patients who had additional coronary bypass grafts the mean left ventricular end-diastolic pressure was unchanged and abnormally high after a mean follow-up period of nearly two years. One explanation for the lack of improvement in left ventricular function in these patients, as compared with those with no progression of coronary disease also followed for this period, may be the existence of more extensive disease before operation. Six is too small a number from which to draw any conclusions, but Schönbeck et al. ${ }^{6}$ found no improvement in left ventricular end-diastolic pressure in 13 patients restudied by coronary angiography at a mean of 13 months after aneurysmectomy and eight of these had a coronary bypass.

\section{References}

1 Cooley DA, Collins HA, Morris GC Jr, Chapman DW. Ventricular aneurysm after myocardial infarction: surgical excision with use of temporary cardiopulmonary bypass. $\mathcal{F} A M A$ 1958; 167: 557-60.

2 Donaldson RM, Honey M, Balcon R, Banim SO, Sturridge MF, Wright JEC. Surgical treatment of postinfarction left ventricular aneurysm in 32 patients. Br Heart $\mathcal{F}$ 1976; 38: 1223-8.

3 Loop FD, Effler DB, Navia JA, Sheldon WC, Groves LK. Aneurysms of the left ventricle: survival and results of a ten-year surgical experience. Ann Surg 1973; 178: 399-405.

4 Stoney WS, Alford WC Jr, Burrus GR, Thomas CS Jr. Repair of anteroseptal ventricular aneurysm. Ann Thorac Surg 1973; 15: 394-404.

5 Kitamura S, Echevarria M, Kay JH, et al. Left ventricular performance before and after removal of the noncontractile area of the left ventricle and revascularization of the myocardium. Circulation 1972; 45: 1005-17.

6 Schönbeck M, Senning A, Rutishauser W, et al. Der Einfluss der Aneurysmektomie auf die linksventrikuläre Funktion. Dtsch Med Wochenschr 1975; 100: 77-83.

7 Fisher VJ, Alvarez AJ, Shah A, Dolgin M, Tice DA.
Left ventricular scars. Clinical and haemodynamic results of excision. Br Heart $\mathcal{f} 1974$; 36: 132-8.

8 Frank G, Klein H, Lichtlen P, Borst HG. Spätergebnisse nach linksventrikulärer Aneurysmaresektion. Munch Med Wochenschr 1978; 120: 565-8.

9 Rivera R, Delcan JL. Factors influencing better results in operation for postinfarction ventricular aneurysms. Ann Thorac Surg 1979; 27: 445-50.

10 Sesto M, Schwarz F, Thiedemann KU, Flameng W, Schlepper M. Failure of aneurysmectomy to improve left ventricular function. Br Heart f 1977; 41: 79-88.

11 Trieb G, Schmidt H, Sigwart U, Mertens HM, Gleichmann U, Borst HG. Einfluss der Aneurysmektomie auf die linksventrikuläre Belastungshämodynamik. Herz-Kreislauf 1977; 9: 511-4.

12 Brawley RK, Schaff H, Stevens R, Ducci H, Gott $\mathrm{VL}$, Donahoo JS. Influence of coronary artery anatomy on survival following resection of left ventricular aneurysms and chronic infarcts. $\mathcal{f}$ Thorac Cardiovasc Surg 1977; 73: 120-8.

13 Richter S, Aranada JM, Embi A, Sung R, El-Sherif $\mathrm{N}$, Befeler B. Functional significance of electrocardiographic changes after left ventricular aneurysmectomy. F Electrocardiol 1978; 11, 247-52.

14 Gooch AS, Patel AR, Maranhao V. Persistent ST segment elevation in left ventricular aneurysm before and after surgery. Am Heart $\mathcal{F} 1979 ;$ 98, 11-4.

15 Lusted LB, Keats TE. Atlas of roentgenographic measurement. 3rd ed. Chicago: Year Book Medical Publishers, 1972.

16 Judkins MP. Selective coronary arteriography, Part I. A percutaneous transfemoral technic. Radiology 1967; 89: 815-24.

17 Shaw RC, Ferguson TB, Weldon CS, Connors JP. Left ventricular aneurysm resection: indications and long-term follow-up. Ann Thorac Surg 1978; 25: 336-9.

18 Gewirtz H, Horacek BM, Wolf HK, Rautaharju PM, Smith ER. Mechanism of persistent S-T segment elevation after anterior myocardial infarction. Am F Cardiol 1979; 44: 1269-75.

Requests for reprints to Dr Jan Erik Otterstad, Medical Department B, Rikshospitalet, Oslo 1, Norway. 